\title{
Standardized and modular microfluidic platform for fast Lab on Chip system development
}

\author{
S. Dekker ${ }^{\mathrm{a}}$, W. Buesink ${ }^{\mathrm{b}}$, M. Blom ${ }^{\mathrm{b}}$, M. Alessio ${ }^{\mathrm{c}, \mathrm{d}}$, N. Verplanck $^{\mathrm{c}, \mathrm{d}}$, M. Hihoud $^{\mathrm{e}}$, C. Dehan $^{\mathrm{e}}$, \\ W. César ${ }^{\mathrm{f}}$, A. Le $\mathrm{Nel}^{\mathrm{f}}$, A. van den Berg ${ }^{\mathrm{a}}, \mathrm{M}$. Odijk ${ }^{\mathrm{a}, *}$ \\ a BIOS Lab on Chip Group, MESA+ institute for Nanotechnology, University of Twente, 7500AE, Enschede, Netherlands \\ b Micronit Microtechnologies B.V., Colloseum 15, 7521PV, Enschede, Netherlands \\ ${ }^{\mathrm{c}}$ Univ. Grenoble Alpes, F-38000 Grenoble, France \\ d CEA, LETI, MINATEC Campus, F-38054 Grenoble, France \\ e EVEON, 345 rue Lavoisier, 38330 Montbonnot-Saint-Martin, France \\ ${ }^{\mathrm{f}}$ Fluigent, 1 mail du Professeur Mathé, 94800 Villejuif, France
}

\section{A R T I C L E I N F O}

\section{Article history:}

Received 17 October 2017

Received in revised form 27 March 2018

Accepted 2 April 2018

Available online 22 April 2018

\section{Keywords:}

Microfluidic standardization

Platform

Modular

Commercialization

Microfluidic design

Characterization

\begin{abstract}
A B S T R A C T
Since the Lab on a Chip concept was introduced in the 1990s, a lot of scientific advancements have occurred. However, large scale commercial realization of microfluidic technology is being prevented by the lack of standardization. There seems to be a gap between Lab on a Chip systems developed in the lab and those that are manufacturable on a large scale in a fab. In this paper, we propose a modular platform which makes use of standardized parts. Using this platform, a functional-based method of designing microfluidic systems is envisioned. To obtain a certain microfluidic function, a bottom-up design is made. This results in micro fluidic building blocks that perform a microfluidic function. This microfluidic building block is then stored in a library, ready for reuse in the future. Key characteristics are shown for several basic microfluidic building blocks, developed according to a footprint and interconnect standard by various players in the microfluidic world. Such a library of reusable and interoperable microfluidic building blocks is important to fill the gap between lab and fab, as it reduces the time-to-market by lowering prototype time cycles. The wide support of key European players active in microfluidics, which is shown by an ISO workshop agreement (IWA 23:2016), makes this approach more likely to succeed compared to earlier attempts in modular microfluidics.
\end{abstract}

(c) 2018 Elsevier B.V. All rights reserved.

\section{Introduction}

The concept of Lab on a Chip (LOC) and micro total analysis ( $\mu$ TAS) systems was introduced in 1990 by Manz et al., one of the pioneers in the field [1]. Seventeen years later, the field has already showed major advancement by demonstrating many promising concepts for the various components such as sample prep, separation and detection that are combined into a $\mu$ TAS. Yet in 2006 Whitesides argued that the field had not yet fully reached its potential, discussing the typical struggles faced by new technologies including the ease of use for non-experts, and the transfer of technology from academy to industry [2]. Today, microfluidic technology still has not fully become mainstream technology. It appears

\footnotetext{
* Corresponding author.

E-mail address: m.odijk@utwente.nl (M. Odijk).
}

that there are still many hurdles to overcome when migrating an idea from academics into a product ready for the market [3].

To bridge the gap between academic research efforts and the utilization of microfluidic technologies to address real world problems, standardization is essential [4]. Often, monolithic, by which I mean out of one part, Lab on Chips are developed, integrating several functions onto a single device. This approach often leads to the repeated development of already existing concepts, resulting in long development times. The need for high investments makes it exclusively economic for large volumes. Instead, a modular approach could significantly speed up development and prevent the waste of development resources by not "reinventing the wheel". Less development effort is needed in modular systems as standardized parts of the system can be reused. The electronics industry can be taken as a good example of where such standardization works well. In that industry, standards exist for almost every aspect from package dimensions, to standard classes for printed circuit board manufacturing, to solder joints. The development of stan- 
dards moved the electronics industry from the early "spider web assembly" in the 1950 s to the complex system-on-a-chip technology of today.

To show that standardization doesn't exists, at least up to the level of interoperability, in the state of the art modular microfluidics, a list is made in Table 1. Several papers and industrial efforts to produce modular microfluidic systems are shown. It can be seen that although the systems are modular, they are definitely not standardized and thereby preventing interoperability between various modular systems. The table shows elements needed to obtain a functional system, from interconnects to functional blocks. In our approach standardized footprints and standardized interconnect grids are used, we see a future with interoperable modular blocks to build microfluidic systems. Looking towards the future and bigger production volumes, several examples are included where modularity is used during the design phase; linking functions together, but still producing a monolithic device.

One of the earliest modular concepts was developed by Lammerink et al., introducing the concept of a Mixed Circuit Board (MCB) [5]. The board consisted of a printed circuit board and a polycarbonate substrate, respectively responsible for the electrical and fluidic interconnects between actuator and sensor modules. Others focused more on the interconnect itself Gonzalez et al. [6] described a self-aligning reversible interconnect. Grey et al. [7] used a different approach using plastic press fit couplers to connect tubing to a silicon system. A system similar to the mixed circuit board, but using anodic bonding instead of adhesives, to mount the functional parts on the interconnect parts was developed by Schabmuller et al. [8]

Initial efforts to produce a modular microfluidic system often used silicon or glass, well known from MEMS technology. However, a disadvantage of these materials is that they are only economically feasible if large numbers are produced. For the functional modules this is not a problem, as these can be manufactured in high numbers. However, the interconnect solution is often application-specific and thus tends to be produced in lower numbers.

Wego et al. [9] looked at printed circuit board technology to fabricate integrated microsystems. Printed circuit board technology has less accurate dimensional tolerances then conventional fabrication methods used in the microfluidic field. However it is cheaper, especially when producing low number volumes. By the introduction of polymer layers in the stack, they were able to perform microfluidic functions.

Other materials were also investigated for use in modular systems. Microfluidic assembly blocks, (MABs) made from PDMS were introduced by Rhee et al. [10]. They are mounted side by side and sealed by an adhesive.

Lego(C) was an inspiration for Vittayarukskul et al. [15] who produced a fully reversible microfluidic system based on PDMS Lego blocks. The elasticity of PDMS was used to provide a seal between the blocks. Another plug-and-play system was developed by Yuen [12]. Stereo lithography 3D printing was used to fabricate the blocks for this system, which were interconnected using mini-Luer connections. Miserendino[23] showed a system used a clamping to seal, with patternable silicone micro gaskets between the baseplate and functional blocks.

Strohmeier et al. [11] used a different approach when they defined a functional unit cell. With these functional unit cells they designed centrifugal microfluidics devices. Using modularity in the design phase while still producing a monolithic device. Millet et al. [17] achieved something similar, but then for PDMS devices. On the pouring mold they added Acrylonitrile butadiene styrene (ABS) strings between the various components to create integrated tubing in the casting.

The microfluidic industry itself has also looked for solutions to interconnect microfluidic systems. One example of such a solution is the MATAS platform [20,24]. This platform is based on PCB technology with the addition of an extra layer for the fluidics. Blocks implementing microfluidic functions are placed inside milled cavities in the PCB and are connected to the fluidic layer by using O-rings. The blocks are fixed in place by solder. Another platform was developed by Epigem [21] that is similar to the MATAS platform, but instead of PCB technology it is fully based on thermoplastics. Labsmith opted for a slightly different system in which the modules are mounted on a board and for interconnections tubing is used.

From the above it is clear a large variety of modular platforms exists, both in terms of the level of integration in a single module and the place where the modularity is implemented. Hereby, making reuse of the modules of several platforms difficult.

In the future we foresee modularity in both; physical blocks in the end product and already during the design process. At one end of the spectrum is the unit cell operation approach during the design phase used by Strohmeier et al. [11] and the plug-and-play systems of Yuen et al. [12-14] at the other. However, it would be beneficial if these approaches could be used in conjunction with each other; for example if the auxiliary components of the system are in a plug-and-play fashion while the main chip can be designed using functional units. In this paper we focus on the plugand-play system for auxiliary components. To reach this, some degree of standardization is needed. Unfortunately, development of these modular platforms until now is done mostly independently by small groups of interested parties. The modular platform proposed in this paper strongly argues for standardization. A large multinational consortium is backing and co-developing this standard [25]. The focus lies on the ability to interconnect parts from various suppliers together. With this we hope to attain a flourishing ecosystem in which microfluidic parts produced using various techniques (polymer, glass, and silicon) are both available and interconnectable. To help the end user, a library of standardized parts and functionality is also developed, supported by software managing the complete pipeline from design to the production of a microfluidic system [26]. If we draw another analogy from the electronics industry, this library could be regarded as the catalog of big component suppliers such as Newark and Farnell. Using schematics and routing software, these components together are designed to function as complex electronics devices.

Following our approach, we make use of a combination of microfluidic building blocks (MFBB) and fluidic circuit boards (FCBs). In this approach, the MFBB contains the fluidic functionality and the FCB connects all the building block together in a microfluidic system. Both the MFBBs and FCBs are designed and fabricated by industrial and academic partners according to guidelines, documented in a ISO workshop agreement [27-29]. This standardized approach makes it possible to reuse modules and have them interoperable between several partners. Moreover, it allows for a top-down design approach saving valuable development time. Having industrial partners inside the project gives the prospect of having commercial of the-shelf-parts available in the future.

\section{Standardization and design concepts}

\subsection{Define specification from requirements}

When designing a microfluidic system it is, of course, important to know what the requirements for the individual system are. Moving forward, decisions are made with regard to the specifications of the microfluidic system. From this point, a start is made with the physical realization of the system. In the microfluidic world, a bottom up approach is often used where the fabrication technology plays a large role in the design considerations. An important advan- 
Table 1

overview of modularity in microfluidics.

\begin{tabular}{|c|c|c|c|c|c|c|}
\hline Inventor(s) & Type of fluidic part & Main material & Total system & Typical application field & $\begin{array}{l}\text { Modular in Physical } \\
\text { part/design }\end{array}$ & Reversible \\
\hline \multicolumn{7}{|l|}{ Academics } \\
\hline Lammerink et al. [5] & $\begin{array}{l}\text { Functional blocks } \\
\text { connected by a base board. }\end{array}$ & Si/Glass & Yes & Chemistry & Modularity in physical sense & $\begin{array}{l}\text { No, modules are } \\
\text { permanently fixed to the } \\
\text { base board }\end{array}$ \\
\hline Gonzalez et al. [6] & $\begin{array}{l}\text { Interconnects for assembly } \\
\text { of a modular system }\end{array}$ & Si/Glass & $\begin{array}{l}\text { No, only focused on } \\
\text { interconnect }\end{array}$ & Broad application & Modularity in physical sense & $\begin{array}{l}\text { Yes, Silicone O-ring are } \\
\text { used so the connection is } \\
\text { reversible. }\end{array}$ \\
\hline Gray et al. [7] & $\begin{array}{l}\text { Interconnects for assembly } \\
\text { of a modular } \\
\text { system }\end{array}$ & $\begin{array}{l}\text { SI/Glass device } \\
\text { Plastic Coupler }\end{array}$ & $\begin{array}{l}\text { No, only focused on world } \\
\text { to chip interconnects }\end{array}$ & Broad application & Modularity in physical sense & $\begin{array}{l}\text { Yes, but a new coupler } \\
\text { might be required }\end{array}$ \\
\hline Schabmuller et al. [8] & $\begin{array}{l}\text { Functional blocks } \\
\text { connected by a base board. }\end{array}$ & Si/Glass & Yes & Chemistry & Modularity in physical sense & $\begin{array}{l}\text { No, modules are anodically } \\
\text { bonded to the base plate. }\end{array}$ \\
\hline Wego [9] & $\begin{array}{l}\text { Functional blocks made in } \\
\text { PCB technology }\end{array}$ & Copper plated FR-4 & $\begin{array}{l}\text { No, a few component are } \\
\text { shown in PCB technology }\end{array}$ & Broad application & Modularity in physical sense & $\begin{array}{l}\text { Yes, tubing is used for } \\
\text { interconnection. }\end{array}$ \\
\hline Rhee [10] & $\begin{array}{l}\text { Functional block connected } \\
\text { directly to each other }\end{array}$ & PDMS & Yes & Biological, PCR and cell culturing & Modularity in physical sense & $\begin{array}{l}\text { No, Adhesive is used to } \\
\text { interconnect the blocks }\end{array}$ \\
\hline Strohmeier et al. [11] & $\begin{array}{l}\text { Unit operations connected } \\
\text { together in a monolithic } \\
\text { centrifugal device }\end{array}$ & Mainly polymer & Yes & Broad application & Modularity in design & $\begin{array}{l}\text { No, a monolithic device is } \\
\text { fabricated }\end{array}$ \\
\hline Yuen [12-14] & $\begin{array}{l}\text { System build entirely out } \\
\text { of blocks }\end{array}$ & $\begin{array}{l}\text { Polymer with } 3 \mathrm{~d} \text { printing as } \\
\text { structuring method }\end{array}$ & Yes & Simple systems & Modularity in physical sense & $\begin{array}{l}\text { Yes, a mini Luer or magnet } \\
\text { is used to connect the } \\
\text { blocks. }\end{array}$ \\
\hline Vittayarukskul et al. [15] & $\begin{array}{l}\text { System build entirely out } \\
\text { of blocks }\end{array}$ & PDMS & Yes & Simple systems & Modularity in physical sense & $\begin{array}{l}\text { Yes, compression of PDMS } \\
\text { is used to make a fluidic } \\
\text { seal. }\end{array}$ \\
\hline Shaikh et al. [16] & $\begin{array}{l}\text { Interconnects are made on } \\
\text { a base plate containing } \\
\text { multiple functionalities. }\end{array}$ & $\begin{array}{l}\text { PDMS } \\
\text { Silicon }\end{array}$ & Yes & Biochemical analysis & Modularity in design & $\begin{array}{l}\text { Not easy, as the PDMS is } \\
\text { bonded to the Silicon. }\end{array}$ \\
\hline Millet et al. [17] & $\begin{array}{l}\text { Functional units are } \\
\text { connected by } 3 \mathrm{~d} \text { tubes }\end{array}$ & PDMS & Yes & Biochemical analysis & Modularity in design & $\begin{array}{l}\text { No, a monolithic PDMS } \\
\text { device is casted. }\end{array}$ \\
\hline Bhargava et al. [18] & $\begin{array}{l}\text { System build entirely out } \\
\text { of blocks }\end{array}$ & $\begin{array}{l}\text { Polymer with 3d printing as } \\
\text { structuring method }\end{array}$ & Yes & Droplet based applications & Modularity in physical sense & $\begin{array}{l}\text { Yes, an elastic reversible } \\
\text { seal is used }\end{array}$ \\
\hline Loskill et al. [19] & $\begin{array}{l}\text { Different organ chambers, } \\
\text { interconnectable with } \\
\text { connectors }\end{array}$ & PDMS & Yes & Organ-on-a-chip & Modularity in physical sense & $\begin{array}{l}\text { Yes, connections made } \\
\text { with the connector blocks } \\
\text { are reversible }\end{array}$ \\
\hline \multicolumn{7}{|c|}{ - } \\
\hline Lionix $[20]$ & $\begin{array}{l}\text { Functional blocks are } \\
\text { mounted in a PCB/base } \\
\text { board }\end{array}$ & $\begin{array}{l}\text { FR-4 } \\
\text { Si/Glass }\end{array}$ & Yes & Chemistry & Modularity in physical sense & $\begin{array}{l}\text { Yes, modules are } \\
\text { mechanically fixed by } \\
\text { soldering and sealing is } \\
\text { done with O-rings. }\end{array}$ \\
\hline Epigem [21] & $\begin{array}{l}\text { Functional blocks } \\
\text { connected by a base board }\end{array}$ & Polymer based & Yes & Broad application & Modularity in physical sense & $\begin{array}{l}\text { Yes, modules are } \\
\text { mechanically held down. A } \\
\text { PTFE ferrule provides the } \\
\text { seal }\end{array}$ \\
\hline Labsmith [22] & $\begin{array}{l}\text { Functional blocks mounted } \\
\text { on a base board, connected } \\
\text { by tubing }\end{array}$ & Several & Yes & Broad application & Modularity in physical sense & $\begin{array}{l}\text { Yes, Tubing connectors are } \\
\text { reversible }\end{array}$ \\
\hline
\end{tabular}




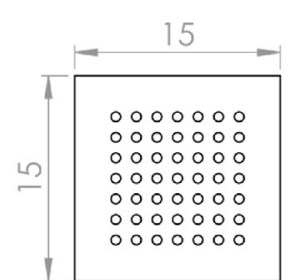

a.

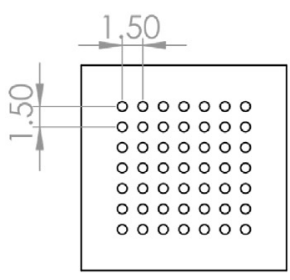

C.

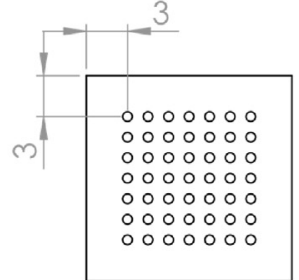

b.

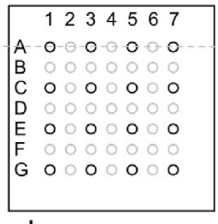

d.

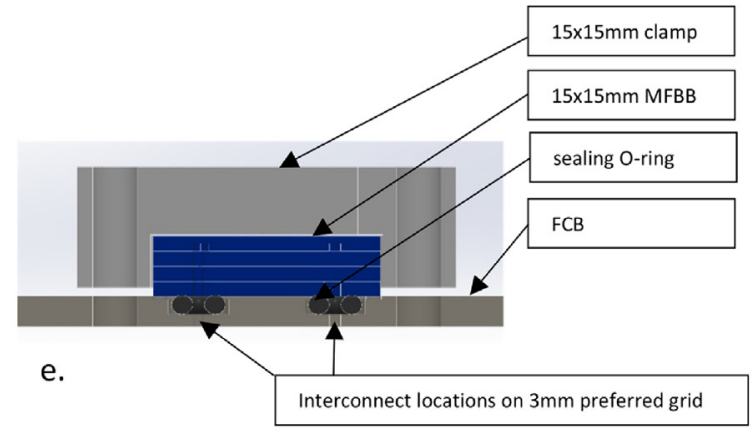

Unit

$\mathrm{mm}$

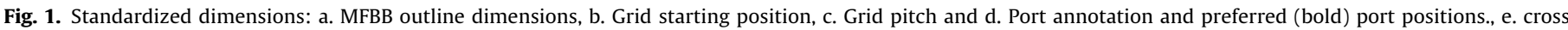
section of figure $d$ in a typical usage scenario, where the MFBB is clamped to the FCB and the seal between them is facilitated by an O-ring.

tage of using a modular platform is that the functional design and physical design can be decoupled. Again, using the analogy with the electronics industry, this would translate to the functional design described by a schematic, while the physical design is the layout of all the transistors inside an integrated circuit. Accordingly, a top down design scheme can be used for the development of the microfluidic system.

\subsection{Functional vs. physical design}

This decoupling of the functional design and physical design makes it possible to work with standardized functional blocks, which only need to be designed and created once. These standardized functional blocks give a microfluidic designer the opportunity to focus merely on the function of a microfluidic system. For this system of standardized microfluidic blocks, most of the common functions should be available to the designer in a standard form. The designer should also have the opportunity to design new blocks that have a specific functionality, but which still conforms to the standard. A designer can be assisted by making use of a CAD system. A library containing the functional building blocks helps the designer to quickly create a new microfluidic system and prevents the reinvention of the wheel often seen in microfluidics.

\subsection{Flexibility}

The flexibility in this system is the freedom to choose how to interconnect the building blocks together. This flexibility finds its implementation in the FCB. This means that each system has its own custom implementation of a FCB. Nevertheless, the interface between the FCB and the MFBB remains standardized. This provides practical advantages such as the second sourcing of parts from various suppliers and the ability to interchange building blocks that have slightly varying functionality. Most of the interfacing hardware is situated in the FCB, so the interfacing can be made to fit the requirements that are specific to a particular application.

\section{Standardization in physical dimensions}

To make this building block and FCB combination work, interoperability between the various components is needed. Therefore, there is a need to standardize the outside dimensions. This makes it possible to use a standardized system to connect the building blocks to the FCB. To align the ports, a standard grid is used as shown in Fig. 1. Inlet and outlets are placed on this grid. Furthermore, the standard dictates that the sealing between the FCB and MFBB is realized in the FCB, which seals to the flat bottom of the MFBB. How this seal is realized is up to the manufacturer of the FCB, providing a possibility for industrial partners to distinguish themselves. An example with O-rings is shown in Fig. 1E.

Within the standard framework, there are several options (see [28] for full list) for the outside dimensions of the MFBB: for smaller chips $15 \times 15 \mathrm{~mm}$ or a multiple of $15 \mathrm{~mm}$ such as $15 \times 30 \mathrm{~mm}$. For larger chips, the standard includes outer dimensions of $75 \times 25 \mathrm{~mm}$, $75 \times 50 \mathrm{~mm}$ and $84 \times 54 \mathrm{~mm}$. These large sizes are similar to the already common formats such as the microscopy slide, or the credit card in the microfluidic world.

The pitch, as can be seen in Fig. 1, is also chosen to be compatible with already currently used formats (e.g. microtiter plate) in the microfluidic world, while still trying to obtain a small pitch so that high interconnect applications are possible.

Besides fluidic interconnects, a microfluidic system sometimes needs an interconnect which is different than a fluidic one. Electrical and optical interconnects are typical examples. In the electronic field, there are already plenty of standards and products available as it is a much more mature market. The guidelines also recommend using these standard products for example connectors and spring loaded probes, but to group the interconnects in a specific area on the MFBB.

\section{Methods}

The above paragraphs describe a new way of designing microfluidics and the corresponding necessary standardization, which the MFManufacturing consortium [25] is attempting to realize. In this paper, the focus is on various parts needed to design according to this new method, with a focus on the typical auxiliary parts used in a microfluidic system: inlet reservoir, pump, flow and pressure measurement and interfacing. Our approach will also to stay true to the Lab on a Chip concept, rather than the Chip in a Lab which is currently often seen. To be able to design with this functionality driven approach a small part of a library of basic building blocks is 
proposed in Table 2. For six of the MFBBs, a more detailed description, including fabrication details and device characterization tests, are given in the following paragraphs.

\subsection{Differential pressure sensor MFBB}

The pressure sensor building block (as shown in Table 2A) is a package to connect to a Honeywell differential pressure (24PCAFA6D). This package makes it possible to fit this sensor to a FCB using a standardized interface. Together with a hydraulic resistor in the FCB (e.g. a simple channel), this building block can also serve as a flow sensor by measuring a differential pressure drop across this channel.

The material of choice for these building blocks is a COC (Topas grade 6013, Axxicon, The Netherlands). This material is chosen because of its chemical resistance to a wide range of chemicals and the opportunity to scale up production applying methods such as hot embossing or even roll-to-roll hot embossing. This provides the ability to suit applications that will be subject to high chemical constraints and higher production volumes in the future, while for quick prototyping micro-milling was used. To bond the four layers together, solvent assisted thermal bonding was used [30]. A PCB was mounted on top of the MFBB to provide electrical interconnection to the MFBB using a flat flex cable.

\subsection{Clamping $M F B B$}

To connect the building blocks for the FCB, several clamping connectors are developed. These clamps are screwed onto the FCB to fix the MFBB and ensure port alignment and compression of the O-rings to achieve an effective seal. Clamps A (Table 2E) and $B$ (Table 2F) are used if fluidic connections are made between FCB and MFBB. Clamp C (Table 2G) is used if a direct fluidic connection to the MFBB or FCB via tubing is required. All clamps are fabricated by direct milling. The tubing used in combination with clamp $\mathrm{C}$ is connected using ferrules to form a tight fit to the MFBB or FCB.

\subsection{Valve $M F B B$}

CEA-LETI developed a pneumatic valve (see Table 2B), consisting of an assembly of COC layers, including an EPDM diaphragm [31]. This valve is pneumatically actuated. The design is adapted to the end-user application (flowrate, dead volumes, and diaphragm material). Depending on the design, the flowrate can reach $50 \mathrm{~mL} / \mathrm{min}$, and the pneumatic pressure to close the valve is engineered to be between $100 \mathrm{kPa}$ and $500 \mathrm{kPa}$. The footprint (layout, $\mathrm{I} / \mathrm{O}$ position) is identical for all the valves.

\subsection{Pump MFBB}

The pump MFBB is based on the previously patented [32] oscillating rotary piston pump principle (see Table 2D). This pump is manufactured using thermoplastic injection molding using polymers and elastomers that can be adapted to the application.

\subsection{Reservoir MFBB}

The reservoir MFBB (see Table 2C) is fabricated by milling a block of PMMA as a top holder for $1.5 \mathrm{~mL}$ HPLC sample vials. This top block also contains holes for three needles; two of these needles puncture the septum of the vial to be able to apply pressure inside the vial and collect the resulting flow of liquid. The third hole is used for a blunt needle that fits onto tubing and connects the external pressure pump to the MFBB. A layer containing microfluidic channels is

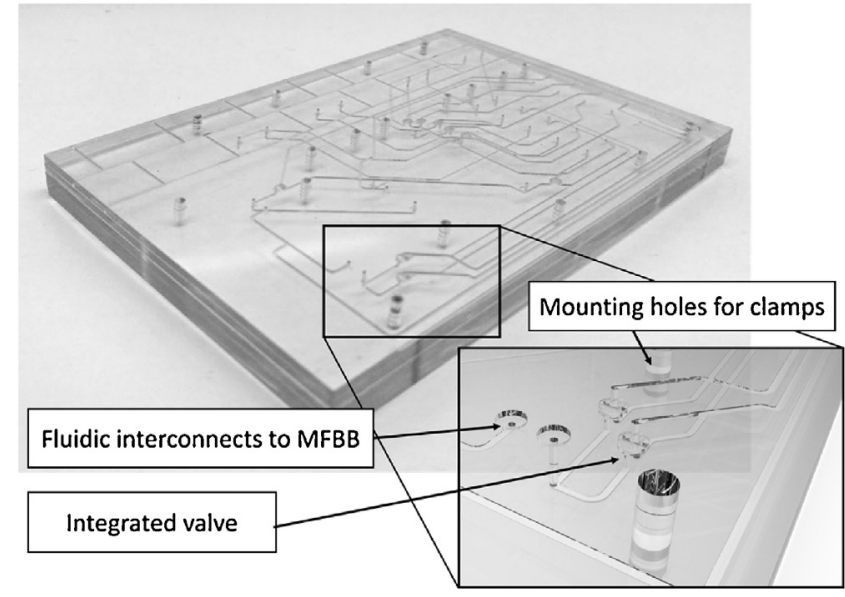

Fig. 2. FCB with integrated valves.

solvent-bonded to this top block to route the fluids or gases from these needles to the desired positions, as defined by the standard.

\subsection{Reaction chamber MFBB}

The reaction chamber is a custom $30 \times 15$ MFBB (see Table $2 \mathrm{H}$ ). The volume of the chamber, the filters and the embedded reagents (powders, beads...) are adapted to the application. Some designs integrate pneumatic valves (see Table $2 \mathrm{~B}$ ). In the example, two $20 \mu \mathrm{m}$ stainless steel filters are embedded in the chamber and $50 \mu \mathrm{m}$ beads are packed between the two filters. The MFBB is composed of two COC layers (or three depending on the designs).

\section{Fluidic circuit board}

The FCB is always a custom part that fits a specific application and interconnects the building blocks in a specific way. Three different types of FCB are discussed with different levels of complexity.

\subsection{Simple polymer-based FCB}

This FCB was developed to test the pressure sensor MFBB, to evaluate how it functions as a flow sensor. This FCB is fabricated in a similar way to the MFBB and consists of two layers of Zeonor 1020R which contains are milled cavities and channels. An assembled version of this FCB is shown in Fig. 3. The channels milled into the first layer are closed off by the second layer by means of solvent bonding. The cavities milled in the top side of the second layer are open to accept the building blocks and to ensure accurate alignment between the channels in the FCB and those in the building block. The interconnect between the FCB and the building block is formed by standard Viton O-rings. There are cavities in the FCB to hold the O-rings in place.

\subsection{Complex polymer-based FCB}

This FCB shown in Fig. 2 incorporates integrated membrane valves for customized flow control to the MFBBs. These membrane valves can be pneumatically actuated to direct flow both from and to MFBBs attached to the FCB. This allows, for instance, the directing of fluids to a mixer chamber and hold these liquids inside the chamber during the mixing process before directing the fluids further. This FCB is fabricated in a similar fashion to that described for the simple FCB also using milling and thermal compression solvent bonding. What makes this FCB complex is that it consist of six layers including a membrane layer. Each layer consists of $1.5 \mathrm{~mm}$ clear 


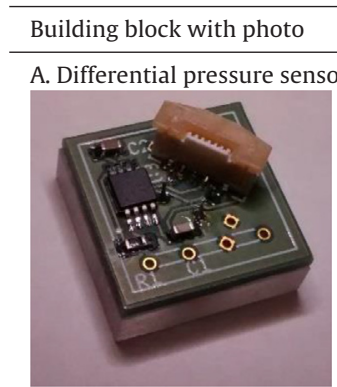

B. Pneumatic valve $15 \times 15 \mathrm{~mm}$
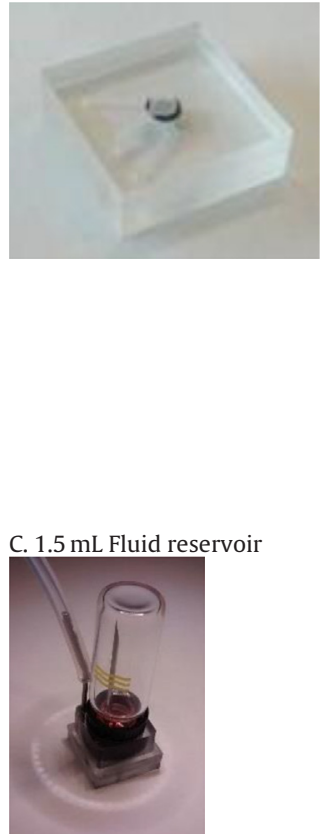

D. High volume pump

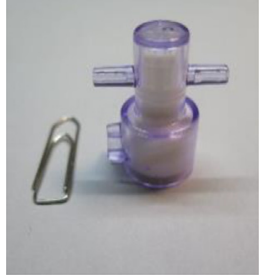

Description

Most relevant characteristics

A building block to measure pressure Due to the

differential nature of the measurement, a flow

measurement is also possible, by measuring pressure drop over a length of channel

A valve building block to conditionally route liquids in microfluidic system. Controlled by pneumatic actuation.

A $1.5 \mathrm{~mL}$ fluid reservoir which can be used to actively push liquid trough a microfluidic system by applying a regulated pressure above the liquid.

A pump capable of obtaining high flow rates even when a large backpressure exists.
Flow characterization ( $R 2=0.98928$ ), Error bars indicate the hysteresis over the 1 repetition of the reference pattern.

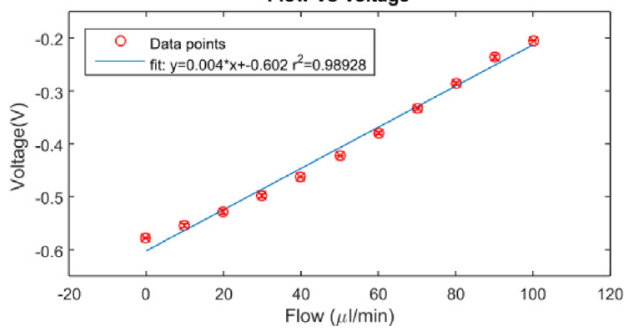

Pressure needed to close MFBB valve. Line for visual guidance.

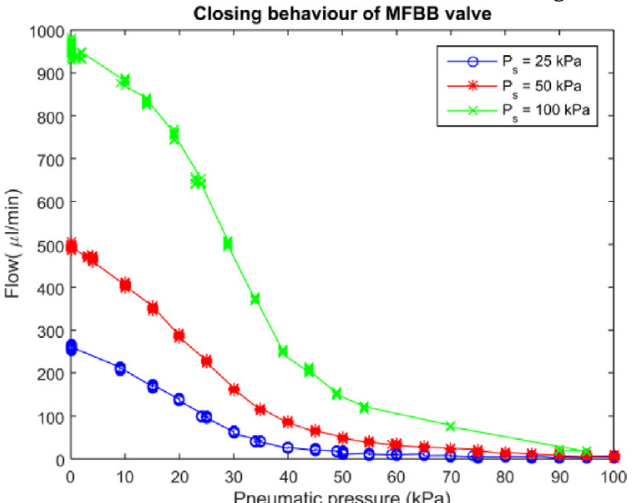

Internal Volume of $1.5 \mathrm{~mL}$

Pumping performance at constant actuation, with respect to changing backpressure.

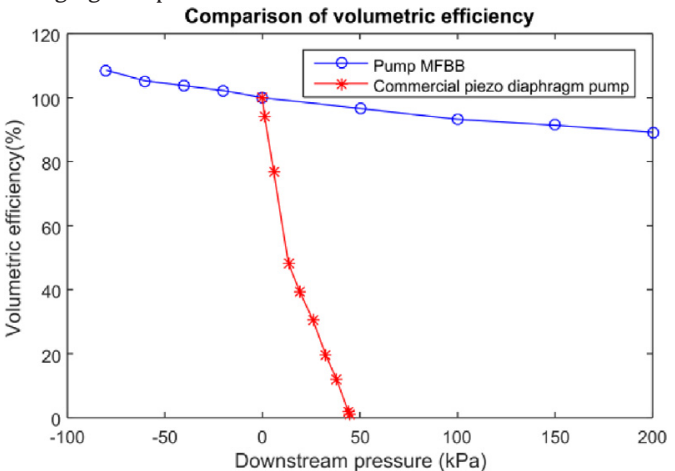


Table 2 (Continued)

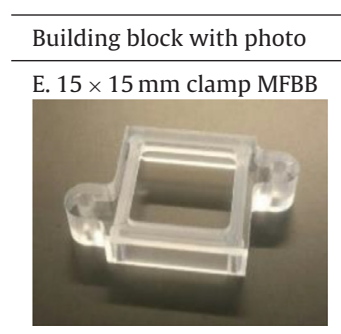
Description

Most relevant characteristics

A clamp to mount a MFBB with $15 \times 15 \mathrm{~mm}$ outer

dimensions to the fluidic circuit board. Also compresses

the O-ring between the FCB and the MFBB to facilitate

sealing.

This clamp is suited to mount devices shown in Table 2A-C

to a fluidic circuit board.

Topline for increasing pressure, bottom line for decreasing

pressure. Line for visual guidance.

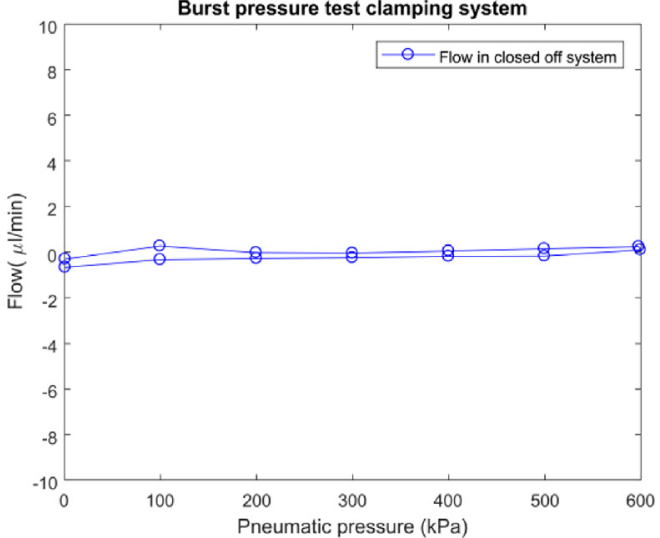

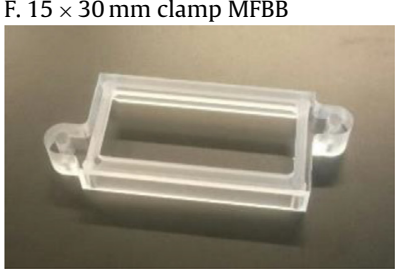

G. Fluidic seal $30 \times 15 \mathrm{~mm}$

clamp MFBB

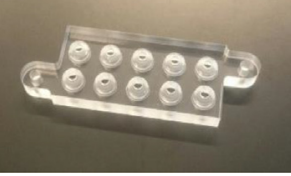

H. Custom reaction chamber $30 \times 15 \mathrm{~mm} \mathrm{MFBB}$

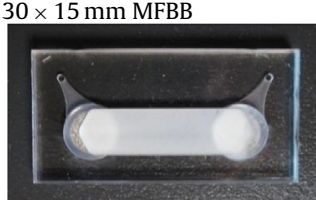

A clamp to mount a MFBB with $15 \times 30 \mathrm{~mm}$ outer

dimensions to the fluidic circuit board. Also compresses

the $\mathrm{O}$-ring between the FCB and the MFBB to facilitate

Similar characteristics to $15 \times 15 \mathrm{~mm}$ clamp

sealing.

This clamp is suited to mount the device shown in

Table $2 \mathrm{H}$.

A building block used to connect 10 individual tubes to a

FCB at once. Elastomeric ferules are used to simultaneously

facilitate sealing between the FCB and the tubes.

Similar characteristics to $15 \times 15 \mathrm{~mm}$ clamp 
polystyrene plates and a SEBS (styrene ethylene butylene ethylene) membrane layer. This SEBS membrane was precisely cut by a $\mathrm{CO} 2$ laser.

\subsection{Glass-based FCB}

In some cases, polymers cannot be used due to their material properties. For one of these cases, a glass FCB is developed. This FCB consists of two borosilicate glass layers. Both glass layers have wet etched channels using two depths of 75 and $200 \mu \mathrm{m}$. After bonding of these two layers, the final channels will be approximately $150 \mu \mathrm{m}$ and $400 \mu \mathrm{m}$ in diameter. The top layer has powder blasted through-holes for top down access, where as in a second design included in the same batch, another FCB allows for direct capillary gluing inside the deep channels from the side. On the top surface of the FCB, platinum electrodes are sputtered to a thickness of $125 \mathrm{~nm}$, using a tantalum seed layer of $15 \mathrm{~nm}$ to improve adhesion. These platinum electrodes are used to create a routing for the electrical actuation of the MFBB valves used in combination with this FCB design. The connection between these MFBBs and the FCB are made using wire bonds. This FCB thereby demonstrates both fluidic and electrical functionality by providing interconnects for both domains.

\section{Test methods}

\subsection{Differential pressure sensor}

The pressure sensor building blocks are characterized both as a pressure sensor and as a flow sensor. For both the pressure and flow characterization, a known pressure or flow is applied to the system by a pressure driven pump (Fluigent MFCS-4C, France). A flow sensor (Fluigent type L, France) was used in a control loop to obtain a reliable flowrate. While applying various flowrates to the system, the output signal of the building block is recorded with a custom-made Labview 2014 application and MyDAQ data acquisition system (National Instruments, The Netherlands). Both the pressure and flow are applied in a staircase pattern which was cycled four times. The pressure/flow of each step in the staircase pattern is kept constant at a plateau value for $30 \mathrm{~s}$. Fig. 3 shows the complete test system, which is based on the simple polymer FCB, and includes the flow sensor MFBB. It consists of four standardized building blocks connected serially, starting with an inlet block, followed by the differential pressure sensor, a blocking plate to allow for future extensions, and an outlet block.

\subsection{Valves integrated in the complex polymer $P C B$}

The valves integrated in the complex polymer-based FCB are tested using a pressure pump (Fluigent MFCS-EZ) fitted with an inline flow sensor (Fluigent type L). The pressure to the valve control channel is varied from 0 to max. $200 \mathrm{kPa}$, while the resulting flow is recorded. This is repeated for three different pressures $(40,60$, $80 \mathrm{kPa}$ ) applied to the reservoir holding the liquid flowing through the valve.

\subsection{Valve $M F B B$}

A valve MFBB is characterized using a custom Fluigent test platform including a two-channel pressure regulator and an in-line flow sensor (Fluigent type XL). The system is run through a dedicated LabVIEW (National Instrument) interface using the Fluigent SDK that provides a fully automated operation and data analysis. The pressure needed to actuate the valve is varied from 0 to $100 \mathrm{kPa}$ in $5 \mathrm{kPa}$ steps. For each step, the flow rate is recorded during a period of $1 \mathrm{~s}$ ( 10 points every $100 \mathrm{~ms}$ ) after waiting for $3 \mathrm{~s}$ to ensure the system is in a steady state condition. This operation is repeated for three fluid inlet pressures $(25 \mathrm{kPa}, 50 \mathrm{kPa}$ and $100 \mathrm{kPa})$.

\subsection{Pump MFBB}

The pump MFBB is characterized using a measurement of the displacement volume in various backpressure conditions. The backpressure pressure is controlled using a closed container, the pump is actuated at a speed of $30 \mathrm{rpm}$ for a given number of cycles. The obtained fluid volume allows the measurement of the pump displacement. The test is repeated for several downstream pressures. The obtained displacement with a backpressure of $0 \mathrm{kPa}$ is normalized to $100 \%$. The efficiency of the pump is calculated based on the ability to sustain this displacement at higher backpressures.

\subsection{Clamping $M F B B$}

The same system as that shown in Fig. 3 is used for leak testing. The clamping MFBB was attached to the FCB using four bolts for each MFBB. A Viton O-ring, placed in a recess in the FCB, provides the seal between the MFBBs and the FCB. Only an inlet block was used, while the other ports on the FCB were capped by a blocking plate. To test for leaks, the system was filled with DI water before positioning the final blocking plate. The pressure at the inlet was applied by a pressure-driven pump (Fluigent MFCS-4C, France) in a range from $0 \mathrm{kPa}$ to $600 \mathrm{kPa}$. A flow sensor (Fluigent type L, France) was placed in line to check if the flow remained at zero. The pressure was applied in a staircase pattern both upwards and downwards. The system was allowed to come to equilibrium before taking a flow measurement.

\section{Results and discussion}

\subsection{Characterization}

\subsubsection{Differential pressure sensor MFBB}

Repackaging this commercial pressure sensor, to comply to the new standard, does not negatively impact its excellent performance. The pressure response still behaves highly linear. With the MFBB connected to the system shown in Fig. 3, its performance as a flow sensor was also evaluated. The figure in Table $2 \mathrm{~A}$ shows the sensor output voltage for varying flow rates. The output of the flow sensor is very linear $(\mathrm{R} 2=0.98928)$. However, a small deviation from perfect linear behavior can be observed. This is probably caused by the fact that the reference flow sensor (Fluigent type L) was operating at low flow rates, outside of its optimum operating range. This suspicion is confirmed by checking the measured flow by the MFBB as a function of the applied pressure by the pump, we again see a highly linear trend.

\subsubsection{High volume pump $M F B B$}

The MFBB pump is able to displace $300 \mu \mathrm{L}$ per cycle, achieving flow rates up to $90 \mathrm{~mL} / \mathrm{min}$. Another key feature is its self-priming, valve less, blocking nature: making the pump suited to particle loaded liquids. More importantly, no fluid flow through the pump is possible when the pump is not driven. This is an advantage when either high or low pressure must be maintained at the ports of the pump before or after pumping phases. The figure in Table 2D shows a sustained displacement for various backpressures. The diaphragm pump is not able to sustain a constant displacement for the various backpressures. Moreover, the pump MFBB is also reversible as it behaves in exactly the same way when the actuation direction is reversed; the inlet becoming the outlet and vice versa. 


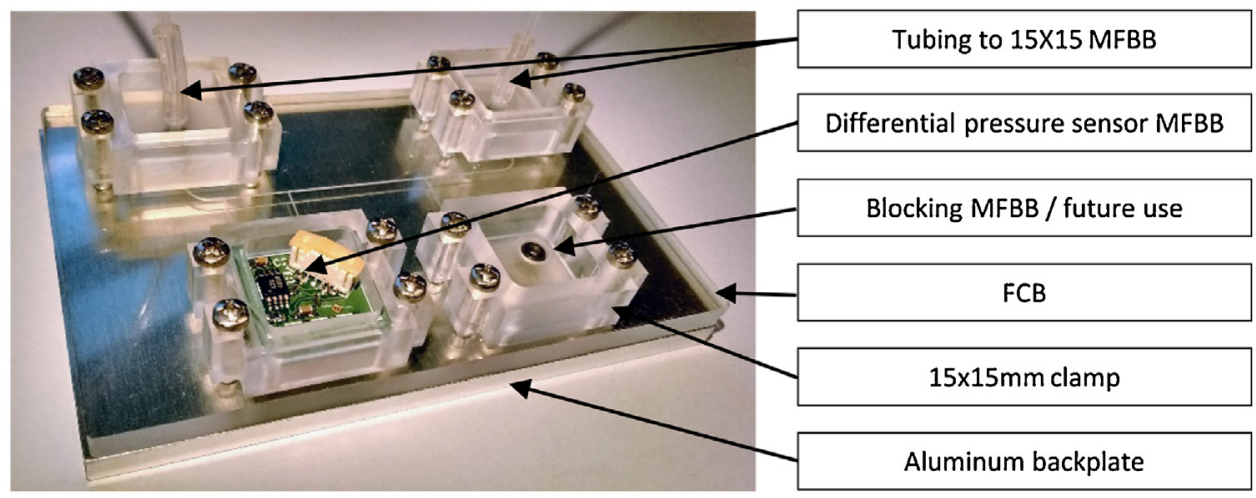

Fig. 3. Complete system to measure flow in fluidic circuit board with mounted MFBBs.

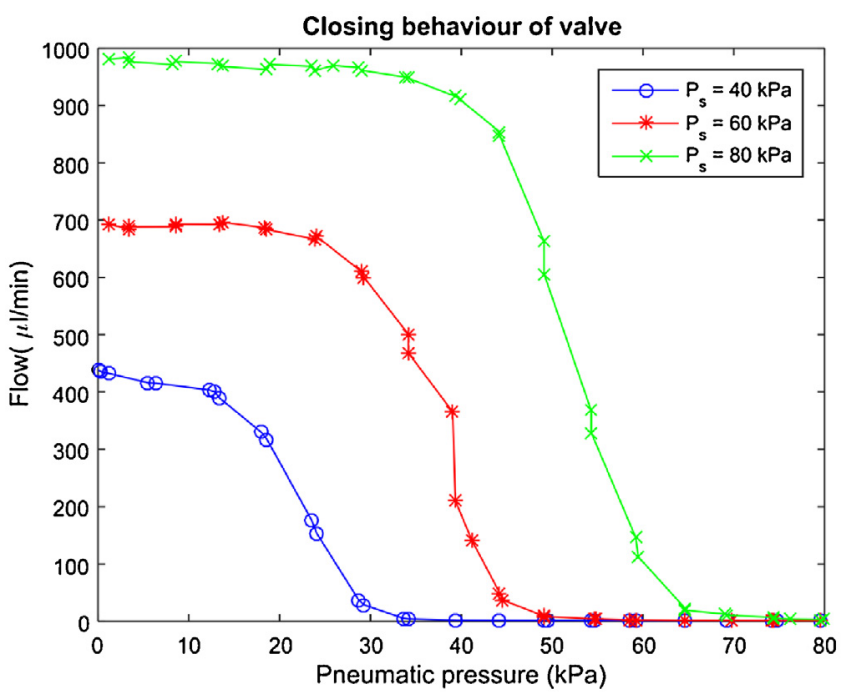

Fig. 4. Closing pressure of an integrated valve. Line for visual guidance.

\subsubsection{Valve $M F B B$}

The figure in Table 2B shows the closure behavior of the MFBB valve. The results shows that by applying sufficient pressure to the control line, the valve can be closed for all three input pressures. When pressures higher than the fluid pressure are applied to the control line, the flow is reduced.

\subsubsection{Integrated $F C B$ valve from the complex $F C B$ design}

Fig. 4 shows the closure behavior of the integrated valves in the complex FCB design. In Fig. 4, three lines are visible for various pressures (Ps) applied to the reservoir holding the liquid flowing through the valve. As expected, the valves are able to close and stop the flow if sufficient pressure is applied to the control channels. A control pressure equal to the pressure applied to the liquid reservoir results in closure of the valve.

\subsubsection{Clamping $M F B B$}

The figure in Table 2E shows the O-ring seals between the FCB and MFBB up to a pressure of at least $600 \mathrm{kPa}$. When the pressure is increased from 0 to $100 \mathrm{kPa}$ there is a slight positive flow, whereas for the decreasing steps the opposite effect is seen. This can be explained by the air that was trapped in the system being compressed and relaxing, allowing liquid to flow into the system and out again.

\subsubsection{Design considerations}

The current state of standardization is compatible with frequently used fabrication technologies, including less accurate technologies like direct milling. This results in relatively large building blocks for microfluidic systems, with long channels to connect these blocks. Trade-offs between for example dead-volume and pressure drop over the channels need to be made. The various $90^{\circ}$ corners, the fluid encounters, traveling from the FCB to the MFBB and back can have unintended behavior like bubble trapping, adding dead volume or mixing. These drawbacks of a modular platform are not necessarily a problem, by integrating sensitive parts in the MFBB and having robust input and outputs on the MFBB.

\section{Conclusions}

In this paper, we have proposed a modular platform that uses standard microfluidic building blocks. Together with a rapid manufacturing processes, this demonstrates a unique platform for quick and straightforward research and development. This is especially important to reduce the existing gap for applications to bridge the lab-to-fab gap, by reducing the time-to-market. This is mainly achieved by separating the functional and physical design by using a top-down design approach. We have developed several building blocks with basic functionality including reservoirs, valves, flow and pressure sensors, and a high volume pump. During development materials were chosen to be compatible with quick prototyping fabrication, but also scalable to other manufacturing techniques to achieve higher volumes. We show how these building blocks can be combined by using a FCB. The use of standards, in both the MFBB and interconnects, allows straightforward and rapid development of early prototypes. Moreover, it demonstrates the combined use of a variety of fabrication technologies in several materials such as glass, polymers and silicon. The combined use of these is difficult to achieve in a traditional monolithic lab-on-chip device. In the future, we will develop more building blocks to extend our library. This library will be made available in 2017 through the Microfluidics Manufacturing website [25] and on-line through a marketplace [26] to enable broad adoption by the microfluidics community. The wide support of key European players that are active in both manufacturing, design and equipment for microfluidics is what will make the difference compared to earlier attempts at modular microfluidics design.

\section{Acknowledgements and contributions}

Henne van Heeren (EnablingMNT) is gratefully acknowledged for his input on standardization in this paper. Hans de Boer and Jan van Nieuwkasteele are acknowledged for technical support. 
This work was supported by ENIAC Joint Undertaking (JU), a public-private partnership focusing on nanoelectronics that brings together ENIAC Member/Associated States, the European Commission, and AENEAS (an association representing European R\&D actors in this field).

The valve MFBB is developed by CEA, both the complex polymer and glass FCB, and the clamps are developed by Micronit. Eveon developed the high volume pump MFBB, while the pressure/flow sensor, liquid reservoir, and simple FCB is developed by the University of Twente.

\section{References}

[1] A. Manz, N. Graber, H.M. Widmer, Miniaturized total chemical analysis systems: a novel concept for chemical sensing, Sens. Actuators B Chem. (1990) 244-248, http://dx.doi.org/10.1016/0925-4005(90)80209-I.

[2] G.M. Whitesides, The origins and the future of microfluidics, Nature 442 (2006) 368-373, http://dx.doi.org/10.1038/nature05058.

[3] R. Mukhopadhyay, Microfluidics on the slope of enlightenment, Anal. Chem. 81 (2009) 4169-4173, http://dx.doi.org/10.1021/ac900638w.

[4] H. van Heeren, Standards for connecting microfluidic devices? Lab Chip 12 (2012) 1022, http://dx.doi.org/10.1039/c2lc20937c.

[5] T.S.J. Lammerink, V.L. Spiering, M. Elwenspoek, J.H.J. Fluitman, A. van den Berg, Modular concept for fluid handling systems. A demonstrator micro analysis system, Proc. Ninth Int. Work. Micro Electromechanical Syst., IEEE (1996) 389-394, http://dx.doi.org/10.1109/MEMSYS.1996.494013.

[6] C. González, S.D. Collins, R.L. Smith, Fluidic interconnects for modular assembly of chemical microsystems, Sens. Actuators B Chem. 49 (1998) 40-45, http://dx.doi.org/10.1016/S0925-4005(98)00035-5.

[7] B.L. Gray, D. Jaeggi, N.J. Mourlas, B.P. van Drieënhuizen, K.R. Williams, N.I Maluf, G.T.A. Kovacs, Novel interconnection technologies for integrated microfluidic systems, Sens. Actuators A Phys. 77 (1999) 57-65, http://dx.doi. org/10.1016/S0924-4247(99)00185-5.

[8] C.G.J. Schabmueller, M. Koch, A.G.R. Evans, A. Brunnschweiler, Design and fabrication of a microfluidic circuitboard, J. Micromech. Microeng. 9 (1999) 176-179, http://dx.doi.org/10.1088/0960-1317/9/2/318.

[9] A. Wego, S. Richter, L. Pagel, Fluidic microsystems based on printed circuit board technology, J. Micromech. Microeng. 11 (2001) 528-531, http://dx.doi. org/10.1088/0960-1317/11/5/313.

[10] M. Rhee, M.A. Burns, Microfluidic assembly blocks, Lab Chip 8 (2008) 1365, http://dx.doi.org/10.1039/b805137b.

[11] O. Strohmeier, M. Keller, F. Schwemmer, S. Zehnle, D. Mark, F. von Stetten, R. Zengerle, N. Paust, Centrifugal microfluidic platforms: advanced unit operations and applications, Chem. Soc. Rev. 44 (2015) 6187-6229, http://dx doi.org/10.1039/C4CS00371C.

[12] P.K. Yuen, SmartBuild-A truly plug-n-play modular microfluidic system, Lab Chip 8 (2008) 1374, http://dx.doi.org/10.1039/b805086d.

[13] P.K. Yuen, J.T. Bliss, C.C. Thompson, R.C. Peterson, Multidimensional modular microfluidic system, Lab Chip 9 (2009) 3303, http://dx.doi.org/10.1039/ b912295h.

[14] P.K. Yuen, A reconfigurable stick-n-play modular microfluidic system using magnetic interconnects, Lab Chip 16 (2016) 3700-3707, http://dx.doi.org/10 1039/C6LC00741D.

[15] K. Vittayarukskul, A.P. Lee, A truly Lego ${ }^{\circledR}$ - like modular microfluidics platform, J. Micromech. Microeng. 27 (2017) 35004, http://dx.doi.org/10. 1088/1361-6439/aa53ed.

[16] K.A. Shaikh, K.S. Ryu, E.D. Goluch, J.-M. Nam, J. Liu, C.S. Thaxton, T.N. Chiesl, A.E. Barron, Y. Lu, C.A. Mirkin, C. Liu, A modular microfluidic architecture for integrated biochemical analysis, Proc. Natl. Acad. Sci. 102 (2005) 9745-9750, http://dx.doi.org/10.1073/pnas.0504082102.

[17] L.J. Millet, J.D. Lucheon, R.F. Standaert, S.T. Retterer, M.J. Doktycz, Modular microfluidics for point-of-care protein purifications, Lab Chip 15 (2015) 1799-1811, http://dx.doi.org/10.1039/C5LC00094G.

[18] K.C. Bhargava, B. Thompson, N. Malmstadt, Discrete elements for 3D microfluidics, Proc. Natl. Acad. Sci. U. S. A. 111 (2014) 15013-15018, http://dx doi.org/10.1073/pnas.1414764111.

[19] P. Loskill, S.G. Marcus, A. Mathur, W.M. Reese, K.E. Healy, Morgano: a Lego ${ }^{\circledast}$-like plug \& play system for modular multi-organ-chips, PLoS One 10 (2015) 1-13, http://dx.doi.org/10.1371/journal.pone.0139587.

[20] J. Wissink, MATAS. A Modular Assembly Technology for Hybrid uTAS, 2000 (Accessed 4 August 2014) http://www.lionixbv.nl/download/pdf/MSTnewsfeb2000.pdf.

[21] Ferrules for Micro-fluidic Connectors, 2016 (Accessed 3 September 2016) http://epigem.co.uk/technology/microfluidics/connectors.

[22] Y. Fintschenko, Education A modular approach to microfluidics in the teaching laboratory, Lab Chip 11 (2011) 3394, http://dx.doi.org/10.1039/c1lc90069b.

[23] S. Miserendino, Y.-C. Tai, Modular microfluidic interconnects using photodefinable silicone microgaskets and MEMS O-rings, Sens. Actuators A Phys. 143 (2008) 7-13, http://dx.doi.org/10.1016/j.sna.2007.07.019.

[24] M. Gilde, H. van den Vlekkert, H. Leeuwis, A. Prak, Modular design approach for MicroFluidic systems, Tech. Proc. 2005 NSTI Nanotechnol. Conf. Trade
Show (2005) 684-687 (Accessed 3 October 2017)

www.nsti.org/publications/Nanotech/2005/pdf/1201.pdf

[25] MFManufacturing Project, 2017 (Accessed 28 October 2017) http://mfmanufacturing.eu/.

[26] Microfluidic marketplace, 2017, (Accessed 15 March 2017) http://www. makefluidics.com/.

[27] IWA 23, Interoperability of Microfluidic Devices - Guidelines for Pitch Spacing Dimensions and Initial Device Classification, 2016 http://www.iso. org/iso/home/store/catalogue_tc/catalogue_detail.htm?csnumber=70603.

[28] H. van Heeren, T. Atkins, N. Verplanck, C. Peponnet, P. Hewkin, M. Blom, W. Buesink, J.-E. Bullema, S. Dekker, Design Guideline for Microfluidic Device and Component Interfaces (part 1) Ver. 2, 2016, http://dx.doi.org/10.13140/RG.2. 1.1698.5206.

[29] H. van Heeren, D. Verhoeven, T. Atkins, A. Tzannis, H. Becker, W. Beusink, P. Chen, Design Guideline for Microfluidic Device and Component Interfaces (Part 2) Ver. 1.2, 2016, http://dx.doi.org/10.13140/RG.2.1.3318.9364.

[30] I.R.G. Ogilvie, V.J. Sieben, C.F.A. Floquet, R. Zmijan, M.C. Mowlem, H. Morgan, Solvent processing of PMMA and COC chips for bonding devices with optical quality surfaces, 14th Int. Conf. Miniaturized Syst. Chem. Life Sci. (2010) 1244-1246.

[31] N. VErplanck, N. Sarrut, F. Boizot, M. Alessio, Fluid Card Comprising At Least One Fluid Valve, WO029348 (A1), 2017 (Accessed 16 March 2017) https:// worldwide.espacenet.com/publicationDetails/ biblio?FT=D\&date $=20170223 \& D B=E P O D O C \&$ locale $=\mathrm{fr}_{-}$ $E P \& C C=W O \& N R=2017029348 A 1 \& K C=A 1 \& N D=4$.

[32] A. Wattellier, C. Dehan, Rotary-oscillating Subassembly And Rotary-oscillating Volumetric Pumping Device For Volumetrically Pumping A Fluid, WO011384, 2015, pp.

2015 (Accessed 14 March 2017) https://patentscope.wipo.int/search/en/detail. jsf?docId=WO2015011384\&recNum=1\&maxRec=\&office=\&prevFilter=\&sortOption= \&queryString $=\&$ tab $=$ PCT + Biblio

\section{Biographies}

S. Dekker Stefan Dekker is a PhD student at the University of Twente. He obtained his master in Electrical Engineering at the University of Twente (2014). Currently, he is working on standardization in the field of microfluidics.

W. Buesink Wilfred Buesink is Head of Product Design at Micronit Microtechnologies $\mathrm{BV}$, leading the design team and coordinating the microfluidics business unit. He received a MSc. in mechanical engineering from the University of Twente in 2007 focusing on interfacing for microfluidics.

M. Blom Marko Blom (M), PhD is CTO at Micronit. Prior to this he worked as a research scientist for Polymer Laboratories after completing his PhD entitled "Onchip separation and sensing systems for hydrodynamic chromatography" in 2002 During his PhD and subsequent work Marko has focused on enabling and applying microfabrication and microfluidics techniques for solving challenges in the lab-ona-chip and BioMEMS fields.

M. Alessio M. Alessio graduated from J. Fourier University of Grenoble in the physical measurements department (IUT1) and obtained a professional license (Optronic) in 2006. Since 2009 he is working as manufacturing and packaging technician at CEALeti in the micro-technologies for biology and healthcare division to design and produce microfluidic components and package silicon microsystems.

N. Verplanck Nicolas Verplanck obtained his MSc in Instrumentation at Polytech'Lille, an engineer school from the University of Lille (France) in 2004 in paralle with his MSc in Microtechnology and his PhD at the IEMN/University of Lille (France) in 2007. His work was focused on electrowetting on superhydrophobic surfaces for mass spectrometry. Following this, he joined Varioptic in Lyon (France) as a project leader and developed, from the prototype to the industrialization, a liquid lens for optical image stabilization. From 2011-2013, he held a customer project management position at SMC Pneumatics where he worked with world leading medical companies to provide assembled fluidic components. Since summer 2013, he is working as research engineer and project manager at CEA-LETI in the microtechnologies for biology and healthcare division to manage (i) the development and the production of microfluidic components (lab-on-a-chips and point-of-care) and (ii) the standardization in microfluidics (MFManufacturing project, AFNOR B35A ISO TC48/WG3)

M. Hihoud Majid HIHOUD is Mechanical Engineer at EVEON specialized in actuation and mechatronics. After working in various fields like aeronautics, space and defense industries, he joined EVEON where he contributes to medical devices design and tests.

C. Dehan Christophe Dehan is Business Developper and IP Manager at EVEON. He graduated from ParisTech Arts et Metiers (1987) and obtained his Master of Science in Materials at VPI\&SU USA (1989). He has since pursued customer and outcome focused multidisciplinary innovation in several industries across positions from R\&D Director to Product Management. As R\&D Director when he joined Eveon, he was the co-inventor of core technologies for medical micropumps and automated mixing and reconstitutions systems.

W. César William César is an R\&D project manager at Fluigent, working on various project on flow control systems for microfluidics. He recieved a Ph.D. in engineer- 
ing working on micro-chromatographs and numerical models for indoor air quality monitoring.

A. Le Nel Dr. Anne Le Nel, previously CSO of Fluigent, has been active for more than 12 years in the development and manufacturing of specific instruments and customized products dedicated to different applications in microfluidic. Dr Le Nel led teams that develop microfluidic instruments and platforms for R\&D and oem markets. She has led projects across flow control from proof of concept through product introduction and support. She was in charge of the development and release of the new product ranges of the company from 2012 to 2015 (> 15 products, hardware \& software). Before that, she was in charge of the development of sample preparation instruments for a big French actor in the defense sector integrating preconcentration, lysis and purification steps involving molecular biology, electronics, microfluidics, and mechanics. She is now responsible globally of industrial projects and the OEM business.

A. van den Berg Albert van den Berg received MSc in applied physics in 1983, and his $\mathrm{PhD}$ in 1988 both at the University of Twente, the Netherlands. From 1988-1993 he worked in Neuchatel, Switzerland, at the CSEM and the University (IMT) on miniaturized chemical sensors. From 1993 until 1999 he was research director Micro Tota Analysis Systems ( $\mu$ TAS) at MESA, University of Twente. In 1998 he was appointed as part-time professor "Biochemical Analysis Systems", and later in 2000 as full professor on Miniaturized Systems for (Bio)Chemical Analysis in the faculty of Electrical Engineering.

M. Odijk Mathieu Odijk is an associate professor at the University of Twente, leading the research theme on micro- and nanodevices for Chemical Analysis. He received a Ph.D. in electrical engineering from the University of Twente in 2011, developing electrochemical lab-on-chips to study drug metabolism reactions. His current research focusses on the designing novel nano- and microfabricated tools to tackle challenging analytical measurement problems, unsolvable by traditional methods due to their slow speed, lack of sensitivity, or poor spatial resolution. 